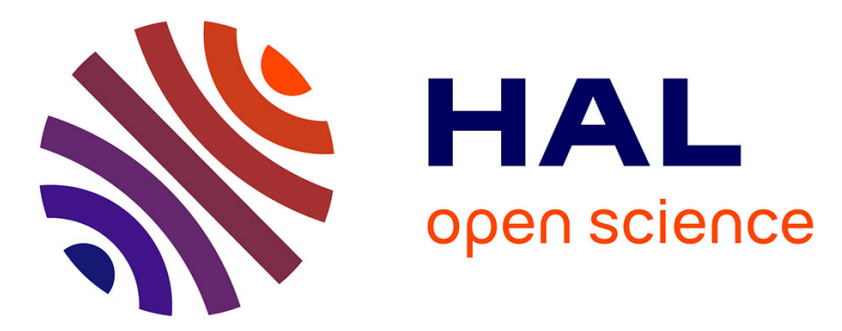

\title{
Novel Dopants for Silica-Based Fiber Amplifiers
}

Bernard Dussardier, Wilfried Blanc

\section{To cite this version:}

Bernard Dussardier, Wilfried Blanc. Novel Dopants for Silica-Based Fiber Amplifiers. Optical Fiber Conference and Exposition and The National Fiber Optic Engineers Conference, Mar 2007, Anaheim, United States. paper OMN1. hal-00589258

\section{HAL Id: hal-00589258 https://hal.science/hal-00589258}

Submitted on 28 Apr 2011

HAL is a multi-disciplinary open access archive for the deposit and dissemination of scientific research documents, whether they are published or not. The documents may come from teaching and research institutions in France or abroad, or from public or private research centers.
L'archive ouverte pluridisciplinaire HAL, est destinée au dépôt et à la diffusion de documents scientifiques de niveau recherche, publiés ou non, émanant des établissements d'enseignement et de recherche français ou étrangers, des laboratoires publics ou privés. 


\title{
OMN1.pdf
}

\section{Novel Dopants for Silica-Based Fiber Amplifiers}

\author{
B. Dussardier, W. Blanc \\ Laboratoire de Physique de la Matière Condensée - UMR 6622 - CNRS/Université de Nice Sophia Antipolis \\ Faculté des Sciences - Parc Valrose - F-06108 Nice CEDEX 2 - France \\ tel.: +33492076748, email: bernard.dussardier@unice.fr
}

\begin{abstract}
We review on some studies of the potential of new dopants in silica fibers for ultrabroadband amplification coverage in the 800-1700 $\mathrm{nm}$ range, including transition metal and rare-earth ions, and sensitized nano-particles.

(C)2006 Optical Society of America

OCIS codes: (060.2320) Fiber optics amplifiers and oscillatorsl; (060.2290) Fiber materials; (060.2410) Fibers, erbium
\end{abstract}

\section{Introduction}

Optical telecommunications systems already benefit from well developped and efficient optical fiber amplifiers operating on broad bands. Reliable, low energy consumption, broadband, flat gain erbium-doped amplifiers (EDFA) are commercially available and installed in the C-band (1535-1565 nm) and in the L-band (1565-1625 nm), where silica losses are the lowest $(<0.2 \mathrm{~dB} / \mathrm{km})$. Even in the S-band $(1460-1530 \mathrm{~nm})$, thulium-doped fluoride glass fiber amplifiers (TDFA) are available. Although the total available amplified bandwidth is not fully used, long term basic research is of great importance in the aim of identifying innovative, cheap, reliable fiber amplifiers on the alreadycovered bands, and offer amplification over a broader spectral width, again using cost effective and very reliable fiber materials.

Thanks to recent improvements of silica fibers fabrication processes, their transmission window is now very wide, allowing telecommunications almost anywhere within the 800-1700 nm window, depending on the transmission distance and application. Some ew telecommunication bands not yet covered by EDFAs (ie unexploited or using passive systems) may in the future require amplification due to the ever growing number of users and applications. Developping active (i.e. amplified) links is therefore interesting in several bands, such as the $1^{\text {st }}$ historical telecommunication window $(850 \mathrm{~nm}$, fiber attenuation $\sim-2 \mathrm{~dB} / \mathrm{km})$, the O-band or $2^{\text {nd }}$ telecommunication window $(1260-1360 \mathrm{~nm}, \sim-0.5 \mathrm{~dB} / \mathrm{km})$. Even the U-band $(1625-1675 \mathrm{~nm}, \sim-0.5 \mathrm{to}-1.0 \mathrm{~dB} / \mathrm{km})$ would be exploitable (Figure 1). Alternative technologies under development are Raman fiber amplifiers (RFAs) and semiconductor amplifiers (SOAs), with some limitations including complex pumping schemes and inter-band crosstalk for RFAs, limited bandwidth per individual SOA, etc...

Besides silica-based EDFAs, other glasses doped with appropriate rare-earth dopants have been proposed to cover the $\mathrm{S}$ and $\mathrm{C}+\mathrm{L}$ bands, sometimes with good characteristics (high quantum efficiency (QE), gain flatness, gain red-shifting,...). Some are even commercially available, such as fluoride- or tellurite- or even mixed coumpounds oxides-glass based EDFAs and TDFAs. However, many issues are still actual in fabricating cheap and reliable fibers using these materials, and fusion splicing to silica components is most of the cases impossible. Therefore silica glass is preferred as glass for cost effectiveness and reliability. The aim of this paper is to review on-going research projects on innovative amplifying dopants implemented in silica-based fibers. Issues that are usually addressed in reports are (1) identifying potential dopants and (2) examine improved manners to incorporate them in silica fibers to obtain spectrally broadened amplification. Investigations concern either conventional bands in the aim of proposing simpler architectures than existing devices, using less components, or amplification over yet uncovered bands. These research activities benefit of contributions from several science fields and technologies: process engineering, glass science, spectroscopy and high resolution material characterization.

\section{Status of the silica transparent window coverage by rare earth doped amplifiers.}

We review here on amplification either experimentally demonstrated and/or commercially available in the 800$1700 \mathrm{~nm}$ range, starting from the long wavelength side. The C- and L-bands are fully covered by silica and nonsilica EDFAs. Some low-phonon energy glasses (oxide and non-oxides) EDFAs offer smoother and red-shifted gain curves, allowing a slight extension of the overall gain curve [1, 2]. S-band is covered only by TDFAs [3], using fluoride or other low-phonon energy glasses [1], except for silica S-band EDFAs covering 1480-1520 nm, using long wavelength amplified spontaneous emission (ASE) filtering scheme [4] or gain clamping complex architecture. The O-band around $1310 \mathrm{~nm}$ is partially covered by praseodymium, only in low-phonon glasses [5], however the $\mathrm{QE}$ is low (4-6\% in fluorides) and $\mathrm{Pr}^{3+}$ is difficult to pump (weak absorption at $\sim 1030 \mathrm{~nm}$ ). At shorter wavelengths, both ytterbium and neodymium ions have gain in the 1050-1150-nm range, whereas using ASE filtering [6], signal 


\section{OMN1.pdf}

amplification should be possible in the 980-1050-nm and 900-950-nm ranges, respectively. At last, thulium shows a narrow 20-nm gain band around $840 \mathrm{~nm}$ in silica [7], although a QE close to unity would be found only in lowphonon energy glasses. Therefore, the main gaps which are not covered yet, even in laboratory experiments, are approximately: $1150-1300 \mathrm{~nm}, 1350-1460 \mathrm{~nm}, 1625-1700 \mathrm{~nm}$. Regarding silica-based only fiber amplifiers, these gaps are larger: $800-900 \mathrm{~nm}, 1150-1490$ and $1625-1700 \mathrm{~nm}$, respectively.

\section{Alternative dopants with potential broad band amplification}

Alternative dopants to erbium, ytterbium and neodymium in silica suffer from multi-phonon non-radiative (MP-NR) relaxations (giving low QE) and/or gain quenching due to bottlenecking on the lowest energy level of the emission transition. Two main causes induce NR decays: (1) a high material phonon energy associated with a relatively small energy gap between the dopant emitting energy level and the level just underneath (as for $\mathrm{Tm}^{3+}$ in both $1 \mathrm{st}$ telecom. window and S-band) and/or (2) a strong electron-phonon coupling to the material, caused by site symmetry distorsion imposed to the dopant, as for transition metals (TM). Silica has a high phonon energy $\left(1100 \mathrm{~cm}^{-1}\right.$, higher than in fluoride glasses $\sim 550 \mathrm{~cm}^{-1}$ ) and offers distorded dopant sites. Therefore it is necessary to develop some kind of local environment engineering for the dopants within the silica glass network. Some examples based exclusively on silica-based doped fibers are discussed below.

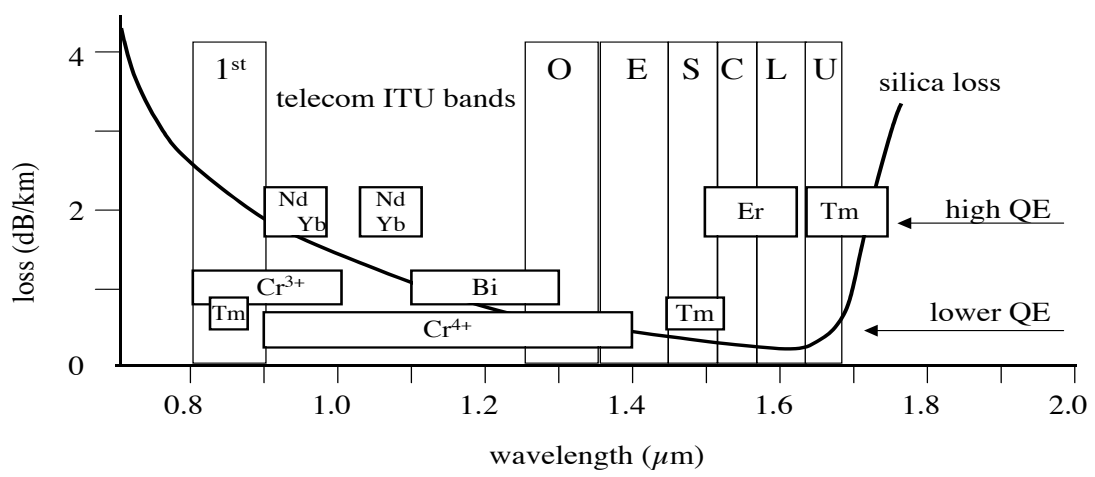

Figure 1: ITU telecommunication bands and possible spectral ranges covered by standard dopants (rare-earth ions operating on high-QE transitions; top line) and alternative dopants (TM and RE ions operating on lower-QE transitions; bottom line) in silicabased fibers.

Thulium: $\mathrm{Tm}^{3+}$ ion has three emission bands at 820,1470 and $1900 \mathrm{~nm}$ respectively. The first two bands both originate from the same ${ }^{3} \mathrm{H}_{4}$ energy level, suffering strong MP-NR decay. In the $1^{\text {st }}$ telecom. window, $11 \mathrm{~dB}$ of gain was measured with $300 \mathrm{~mW}$ of 1064-nm pumping [7] whereas Cole et al. have measured only $7 \mathrm{~dB}$ in the S-band [8]. Both studies concerned MCVD-produced fibres. By simply codoping with aluminium, a 4-fold QE improvement was demonstrated by us and the overall lifetime decay was increased up to $60 \mu$ s. Looking closer to the decay data analysis, we have shown that $\mathrm{Tm}^{3+}$ ions were located in two very different types of sites. One of them is characterized by a almost $100 \mu$ s-lifetime $(\mathrm{QE}=15 \%)$, ever increasing when the Al-content was increased [9]. A better control of the composition and process would increase the overall QE. In the U-band, Tm ${ }^{3+}$ has also some potential using the strong ${ }^{3} \mathrm{~F}_{4}=>^{3} \mathrm{H}_{6}$ emission band usually exploited for $1.9 \mu \mathrm{m}$ laser emission. However, ASE filtering and gain flattening can be applied, as it was theoretically proposed for fluorides U-band TDFAs [10,11].

Chromium: In glasses, TM ions have potentially ten-fold spectrally larger and stronger emission cross-sections than rare-earth ions. Most importantly, their emission bands characteristics are extremely sensitive to local environment [12]. $\mathrm{Cr}^{4+}$ in alumino-silicate fibres has a very broad band from 1000 to $1600 \mathrm{~nm}$ [13], although its QE is very low, due to highly distorded site symmetry[14]. By tuning the fibre composition (particularly in gallo-silicate fibers) and post-drawing heat treating, all chromium ions were stabilized into $\mathrm{Cr}^{3+}$ in a less distorded local environment. QE as high as $10 \%$ and lifetimes equal to $20 \mu \mathrm{s}$ were found [15]. The expected gain curve extends from 800 to $1000 \mathrm{~nm}$, but necessitates visible pump wavelength, around 600-700 nm. It was recently found that the $\mathrm{Cr}^{3+}$ ions were located in nanocrystallites grown during the heat treatment.[16].

Bismuth: Recently, Dvoyrin et al. obtained preliminary results of amplification $(0.2 \mathrm{~dB} / \mathrm{m})$ at $1300 \mathrm{~nm}$ in a Bilow-doped fiber pumped at $1064 \mathrm{~nm}$ at low power. The potential gain band exceeds 1150-1350 nm, as assumed from laser experiments, showing very promosing 20-24\% slope efficiencies [17,18]. The exact nature of the active center responsible for this gain curve is still under study [19]. 


\section{OMN1.pdf}

Activated nanoparticles in silica-based fibers: In order to improve some spectroscopic properties of selected amplifying ions, several research groups are trying to insert them into silica fiber via nanoparticles (NPs) selected for the local composition and site structure they would provide to the dopant. Studies performed in bulk glasses or planar waveguides are encouraging. In silica-based fibers, dielectric particles doped with $\mathrm{Co}^{2+}$ ions were grown by post-drawing heat-treatment in $\mathrm{ZnO}-\mathrm{Al}_{2} \mathrm{O}_{3}-\mathrm{SiO}_{2}$ core glass. Improvement of the absorption and luminescence properties were observed in the $900-\mathrm{nm}$ range, but on a much narrower bandwidth than that of $\mathrm{Cr}^{3+}$ [20]. As mentioned above, $\mathrm{Cr}^{3+}$ ions were stabilized in nanoparticles in gallium-codoped silica fibers, providing luminescence in the 700-1000 nm range, more efficient and broader than in as-drawn $\mathrm{Cr}^{3+} \& \mathrm{Cr}^{4+}$ codoped fibers [16].

\section{Conclusion}

We have reviewed recent reports on alternative dopants for possible amplification range broadening. Although some of the studied alternative dopants suffer MP-NR decays, systematic local-environment improvement must be performed. Also new formulation and local structuration around more standard dopants are of great interest, particularly isolating ions in nanoparticles within the silica glass. Considering all possible dopants, even those of low QE may contribute to fill some spectral gaps in specific applications.

\section{References}

[1] J.Minelly, A.Ellison, “Applications of antimony-silicate glasses for fiber optic amplifiers”, Opt.Fiber Tech. 8, 123-138 (2002).

[2] H. Lin, S. Tanabe, L. Lin, Y.Y. Hou, K. Liu, D.L. Yang, T.C. Ma, J.Y. Yu, E.Y.B. Pun, "Near-infrared emissions with widely different widths in two kinds of $\mathrm{Er}^{3+}$-doped oxide glasses with high refractive indices and low phonon energies", J. Lum. (in press) 2006

[3] T. Komukai, T. Yamamoto, T. Sugawa, Y. Miyajima, "Upconversion pumped Thulium-doped fluoride fiber amplifier and laser operating at $1.47 \mu \mathrm{m}$ ”, IEEE J. Quant. Electron. 31, 1880-1889 (1995).

[4] M. A. Arbore, Y. Zhou, G. Keaton, T. J. Kane, "30 dB gain at $1500 \mathrm{~nm}$ in S-band Erbium-doped silica fiber with distributed ASE suppression", in Proc. SPIE Optical Devices for Fiber Communications IV, 4989, 47-52 (2003).

[5] M. Yamada, M. Shimizu, Y. Ohishi, J. Temmyo, M. Wada, T. Kanamori, M. Horiguchi, S. Takahashi, "15,1-dB-gain Pr ${ }^{3+}$-doped fluoride fiber amplifier pumped by high power laser diode modules", IEEE Photon. Technol. Lett., 9, 994-996 (1992).

[6] M.A. Arbore," Application of fundamental-mode cutoff for novel amplifiers and lasers", in Proc. OFC (OSA, 2005) paper OFB 4

[7] P. R. Watekar, S. Ju, W.-T. Han, "A Nd-YAG laser-pumped Tm-doped silica glass optical fiber amplifier at 840 nm", IEEE Photon. Technol. Lett. 18,1651-1653 (2006)

[8] B. Cole, M.L. Dennis. "S-band amplification in a thulium doped silicate fiber". in Proc. OFC (OSA, 2001), paper TuQ3-1

[9] W. Blanc, C. Michel, Th. Lee Sebastian, B. Faure, M. Ude, B. Dussardier, G. Monnom, "Impact of aluminium codoping on the 1.47 $\mu$ m emission efficiency in a thulium-doped silica fibre", in Proc. ECOC (SEE, 2006), paper Mo4.3.4

[10] C. Kakkar, G. Monnom, K. Thyagarajan, B. Dussardier, "Segmented-Clad Fiber Design for Inherently Gain-Flattened L+-Band TDFA", I EEE Photon. Technol. Lett. 17, 1833-1835 (2005)

[11] C. Kakkar, G. Monnom, K. Thyagarajan, B. Dussardier, "Inherently gain flattened L+ band TDFA based on W-fiber design", Opt. Comm. 262, 193-199 (2006)

[12] B. Dussardier, Y. Guyot,V. Felice, G. Monnom, G. Boulon, "Cr ${ }^{4+}$-doped silica-based optical fibers fluorescence from $0.8 \mu \mathrm{m}$ to $1.7 \mu \mathrm{m}$ ", in Proc. Advanced Solid State Lasers, in TOPS (OSA), 68, 104-108 (2002)

[13] V. Felice, B. Dussardier, J. K. Jones, G. Monnom, D. B. Ostrowsky, "Cr ${ }^{4+}$-doped silica optical fibres : absorption and fluorescence properties », Eur. Phys. J. AP, 11, 107-110 (2000)

[14] V. Felice, B. Dussardier, J. K. Jones, G. Monnom, D. B. Ostrowsky, "Chromium-doped silica optical fibres : influence of the core composition on the Cr oxidation states and crystal field", Opt. Mat. 16 269-277 (2001)

[15] V. V. Dvoyrin, V. M. Mashinsky, V. B. Neustruev, E. M. Dianov, A. N. Guryanov, A. A. Umnikov, "Effective room-temperature luminescence in annealed chromium-doped silicate optical fibers", JOSA B 20, 280-283 (2003)

[16] V.V. Dvoyrin, V.M. Mashinsky, E.M. Dianov, A.A. Umnikov, A.N. Guryanov, B. Dussardier, G. Monnom, "Core nanocrystallization and broadband amplification in chromium-doped silica-based fibers.", J Lum accepted (2006)

[17] E. M. Dianov, V. V. Dvoyrin, V. M. Mashinsky, A. A. Umnikov, M. V. Yashkov, A. N. Guryanov, "Bi-Doped Silica Fiber Laser", in Proc. OFC (OSA, 2006), paper OThJ3

[18] L. Bigot, I. Razdobreev, V. Pureur, A. Favre, G. Bouwmans, M. Douay, "Broadband and efficient bismuth fiber laser around 1.2 $\mu$ m", in Proc. Europhoton Conference (EPS-QEOD, 2006), paper ThE6

[19] V. M. Mashinsky, V. V. Dvoyrin, L. I. Bulatov, I. A. Bufetov, A. V. Shubin, E. F. Kustov, E. M. Dianov, A. A. Umnikov, M. V. Yashkov, A. N. Guryanov, "Bismuth-doped optical fibres - spectroscopic study and interpretation of spectra", in Proc. ECOC (SEE, 2006), paper Mo3.3.6

[20] S. Yoo,U.-C. Paek,W.-T. Han, "Optical properties of the optical fiber containing $\mathrm{Co}^{2+}$-doped $\mathrm{ZnO}_{\mathrm{n}}-\mathrm{Al}_{2} \mathrm{O}_{3}-\mathrm{SiO}_{2}$ glass-ceramics", J. Non Crsyt. Solids 303, 291-295 (2002) 